\title{
Effect of joining temperature on the microstructure and strength of tungsten/ferritic steel joints diffusion bonded with a nickel interlayer
}

\section{$\operatorname{AUTHOR}(\mathrm{S})$ :}

Zhong, Zhihong; Jung, Hun-chea; Hinoki, Tatsuya; Kohyama, Akira

\section{CITATION:}

Zhong, Zhihong ...[et al]. Effect of joining temperature on the microstructure and strength of tungsten/ferritic steel joints diffusion bonded with a nickel interlayer. Journal of Materials Processing Technology 2010, 210(13): 1805-1810

\section{ISSUE DATE:}

2010-10-01

URL:

http://hdl.handle.net/2433/128928

\section{RIGHT:}

(c) 2010 Elsevier B.V.; この論文は出版社版でありません。引用の際には 出版社版をご確認ご利用ください。; This is not the published version. Please cite only the published version. 


\title{
Effect of joining temperature on the microstructure and strength of tungsten/ferritic steel joints diffusion bonded with a nickel interlayer
}

\author{
Zhihong Zhong a,b, Hun-chea Jung c, Tatsuya Hinoki c, ${ }^{\text {, }}$, Akira Kohyama ${ }^{\mathrm{c}}$ \\ ${ }^{a}$ Graduate School of Energy Science, Kyoto University, Gokasho, Uji, Kyoto 611-0011, Japan \\ ${ }^{b}$ New address: National Institute of Materials Science, Sengen, Tsukuba, Ibaraki 305-0047, Japan \\ c Institute of Advanced Energy, Kyoto University, Gokasho, Uji, Kyoto 611-0011, Japan
}

\section{Abstract}

A diffusion bonding process, for joining of tungsten to ferritic steel using nickel as an interlayer, was developed for nuclear component application. The effect of joining temperature on the microstructure and tensile strength of the joint was investigated in this work. Metallographic analysis revealed that a good bonding was obtained at the both tungsten/nickel and nickel/steel interfaces, and the diffusion products were identified in the diffusion zone. Nano-indentation test across the joining interfaces demonstrated the effect of solid solution hardening in the diffusion zone.

Tensile test showed that the maximum average tensile strength of $\sim 200 \mathrm{MPa}$ was obtained for the joint diffusion bonded at $900{ }^{\circ} \mathrm{C}$. The results were discussed in terms of the joining temperature and of the residual stress generated during joining process.

Keywords: Tungsten; Ferritic steel; Diffusion bonding; Microstructure; Joint strength

\footnotetext{
* Corresponding author: Tel: +81-774-38-3461; Fax: +81-774-38-3467.

E-mail address: hinoki@iae.kyoto-u.ac.jp (T. Hinoki); zhong.zhihong@nims.go.jp (Z. Zhong)
} 


\section{Introduction}

In fusion reactors, the plasma facing components (PFCs) are during operation

subjected to high heat flux, high particle flux, and heavy neutron flux, particularly in the divertor region. Helium-cooled divertor concept, which was proposed by Norajitra et al. (2005), is one of the most promising choices for fusion power plant and has recently been received considerable attention. As described by Gervash et al (2007), the development of helium-cooled divertor depends strongly not only on the progress in materials selection, but also on the technology for their manufacturing and joining. As reported in reference of Norajitra et al. (2007), the excellent properties of both tungsten (W) and reduced activation ferritic/martensitic steel make them select as the suitable material candidates for divertor application. Hence, joining of $\mathrm{W}$ to steel is required. However, the conventional fusion welding technique is inapplicable for W/steel system because it requires these two materials with large difference in melting point melt simultaneously. In addition, the large differences in chemical-physical properties of these two materials, especially the coefficients of thermal expansion (CTE) mismatch $\left(4.5 \times 10^{-6} / \mathrm{K}\right.$ for $\mathrm{W}$ and $12-14 \times 10^{-6} / \mathrm{K}$ for steel $)$ may lead to large residual stress in the joints after welding and/or subsequent exposing to mechanical and thermal load. 
These problems in joining of $\mathrm{W}$ to steel by conventional fusion welding could be alleviated by the brazing process, which is considered to be one of the promising methods for the bonding technique of PFCs. Several attempts in brazing of W to steel with using residual stress compensation immediate layer have been made in recent years and successes have been obtained to some extent. Kalin et al. (2004) developed a rapidly solidified foil-type Ni-based filler metal to braze $\mathrm{W}$ to steel using FeNi alloy as the interlayer. They (Kalin et al. 2007) also developed Fe-base alloy for W/steel brazing. Although the developed brazing alloys were effective for W/steel joining from the metallurgical compatibility point of view, the brazing temperature, $1150{ }^{\circ} \mathrm{C}$, was high enough to cause the grain coarsening in steel, and consequently lead to properties degradation. Plasma spraying technique also provides a way of combining $\mathrm{W}$ to steel, as demonstrated by Greuner et al. (2005). However, a further optimization of the processing parameters is needed to reduce the porosity (up to $30 \%$ ) of the coating. Diffusion bonding can avoid the problems mentioned earlier (high joining temperature or low density of coating) and can be used to produce a joint which could be serviced at potential high temperature. Hirose et al. (2006) directly bonded $\mathrm{W}$ to steel at $960{ }^{\circ} \mathrm{C}$ by spark plasma sintering method, but the residual stress concentration and crack initiation are highly possible due to the CTE mismatch between $\mathrm{W}$ and steel. Therefore, an 
interlayer is usually necessary to reduce the residual stress and to prevent the formation of brittle intermetallic compounds such as $\mathrm{FeW}$ and $\mathrm{Fe}_{7} \mathrm{~W}_{6}$.

In the present work, efforts have been made to exploit the beneficial effect of lower joining temperature with an intention to reduce the residual stresses, and to minimize the brittle intermetallic compounds formation between $\mathrm{W}$ and ferritic steel by inserting nickel (Ni) interlayer. Ni was selected as intermediate material because it forms continuous solid solutions with iron at high temperature and no intermetallic formation in $\mathrm{Ni}$ /stainless steel diffusion couple as reported by Kundu and Chatterjee (2006). Additionally, the Ni-W binary phase diagram (Yu et al. 1987) indicates a solid solution of tungsten in nickel, although the formation of some intermetallic phases.

What is more, the yield stress of $\mathrm{Ni}(\sim 150 \mathrm{MPa})$ is lower than that of the base materials, which is expected in favor of the residual stress relaxation in the joints during cooling. The aim of this work is to investigate the influence of joining temperature on the interfacial microstructure and mechanical strength of the diffusion bonded W/steel joints.

\section{Experimental procedure}


Fe-17Cr ferritic steel (FS) plate with the dimension of $300^{\mathrm{L}} \times 100^{\mathrm{W}} \times 2^{\mathrm{T}} \mathrm{mm}$ and the commercially pure $\mathrm{W}$ plate $\left(99.95 \%\right.$ in purity, $\left.100^{\mathrm{L}} \times 100^{\mathrm{W}} \times 2^{\mathrm{T}} \mathrm{mm}\right)$ were used in this work. The chemical compositions and room temperature tensile properties of the both materials are given in Tables 1 and 2, respectively. W and FS were cut into small pieces with the dimensions of $2^{\mathrm{L}} \times 22^{\mathrm{W}} \times 2^{\mathrm{T}}$ and $22^{\mathrm{L}} \times 22^{\mathrm{W}} \times 2^{\mathrm{T}} \mathrm{mm}$, respectively. The bonding surface of the base materials were prepared by conventional polishing techniques and finally polished with sand paper up to 1500 grit. The commercial Ni foil ( $99.9 \%$ in purity, $0.3 \mathrm{~mm}$ thick) was used as intermediate material and both the surfaces of the interlayer were polished by the same procedure. All the materials need to be bonded were cleaned in an ultrasonic bath with acetone for $10 \mathrm{~min}$ and dried in air prior to joining. The prepared materials were then sandwiched as a FS/Ni/W/Ni/FS assembly and followed by mounted in a graphite mould. Diffusion bonding of the assembly was conducted at 850,900 , and $950{ }^{\circ} \mathrm{C}$ for $1.5 \mathrm{~h}$ in a vacuum hot-pressing furnace. The temperature was raised to $550{ }^{\circ} \mathrm{C}$ at a slow heating rate of $5{ }^{\circ} \mathrm{C} / \mathrm{min}$ to keep the high vacuum and then heated up to the assigned joining temperature at 10 ${ }^{\circ} \mathrm{C} / \mathrm{min}$; the cooling rate was $5{ }^{\circ} \mathrm{C} / \mathrm{min}$ down to $400{ }^{\circ} \mathrm{C}$, followed by cooled slowly in vacuum. During this bonding cycle, the vacuum in the furnace was kept below $10^{-2} \mathrm{~Pa}$. A load of $10 \mathrm{MPa}$ was applied along the longitudinal direction of the assembly. 
The cross-sections of the diffusion bonded joints were cut perpendicularly to the joining interface and were prepared for metallographic examination by standard polishing techniques up to $1 \mu \mathrm{m}$. The polished samples were examined in a fieldemission scanning electron microscope (FE-SEM) to characterize the interfacial microstructure. The distribution of various elements across the bonded zones was determined by energy dispersive spectroscopy (EDS) and electron probe microanalysis (EPMA). Pure elemental standards were used for the conversion of X-ray intensities into compositions. Hardness distribution across the joining interface was determined by a nano-indenter, in order to evaluate the micro-mechanical properties at the interfaces. The strength of the joint at ambient temperature was evaluated in a tensile testing machine (Instron 5581) using sub-size specimen $\left(45^{\mathrm{L}} \times 2.0^{\mathrm{W}} \times 1.8^{\mathrm{T}} \mathrm{mm}\right)$ at a crosshead speed of $0.5 \mathrm{~mm} / \mathrm{min}$. Five samples were tested for each process parameter. The fractured surfaces after tensile test were observed with FE-SEM.

\section{Results and discussion}

\subsection{Microstructural characterization of the diffusion zone}

The interfacial microstructures of the joint are shown in Figs. 1 and 2. The 
joints were well-bonded and free from pores. As for the W/Ni interfaces (Fig. 1), one continuous layer, whose thickness depends on the joining temperature, can be distinguished in the diffusion zone between $\mathrm{W}$ and $\mathrm{Ni}$, for the joint bonded at 850 and $900{ }^{\circ} \mathrm{C}$. Apparently, this diffusion layer was formed in the bonding process due to the interdiffusion of nickel and tungsten atoms. A layer of about 3.5 and $6 \mu \mathrm{m}$ thick, which was identified by EDS to be a Ni-rich solid solution $\mathrm{Ni}(\mathrm{W})$, has formed between the $\mathrm{W}$ and $\mathrm{Ni}$, for the joint bonded at 850 and $900{ }^{\circ} \mathrm{C}$, respectively. This is consistent with the equilibrium W-Ni phase diagram (Yu, et al. 1987). A very thin layer, which was identified to be $\mathrm{Ni}_{4}(\mathrm{~W})$, was also observed between $\mathrm{W}$ and $\mathrm{Ni}(\mathrm{W})$ for the $950{ }^{\circ} \mathrm{C}$ joint, as revealed in Fig. 1 (c) and Fig. 2(a). The $\mathrm{Ni}_{4}(\mathrm{~W})$ may be formed by the diffusion of tungsten into $\mathrm{Ni}(\mathrm{W})$. Considering the purpose of this study, the joining temperature higher than $950{ }^{\circ} \mathrm{C}$ was unexpected because the intermetallic compounds decrease the strength of the W/Ni/FS joints (see Section 3.2).

At all the FS/Ni interfaces which bonded at the temperatures of interest, reaction products were not detected in the diffusion zone, at least within the resolution limit of SEM, as shown in Fig. 3. By the electron probe microanalysis, iron, chromium and nickel concentrations changed smoothly in the diffusion zone (Fig. 2(b)), which indicates the absence of intermetallic compounds. The presence of iron and chromium 
in the Ni side indicates certain mount of diffusion of the two main chemical species in ferritic steel occurred at bonding temperatures. Meanwhile, nickel also migrates to the FS during bonding.

The basic criterion for the formation of intermetallic compound during interdiffusion of chemical species is that the compound must first nucleate and then grow. The phase will nucleate in the diffusion zone when two types of atoms attain the composition to the stoichiometry of that phase. And then it will grow into a sizable phase if the rates of the two diffusion species are such that the flux of species arriving at the interface is more than that leaving the phase. At the W/Ni interface, the nucleation and growth of $\mathrm{Ni}$-rich $\mathrm{Ni}(\mathrm{W})$ solid solution and intermetallic phases $\mathrm{Ni}_{4} \mathrm{~W}, \mathrm{NiW}$, and $\mathrm{NiW}_{2}$ are possible in principle as predicted in the $\mathrm{W}-\mathrm{Ni}$ phase diagram, since the composition of these phases could be attained in the diffusion zone when the joints exposed to above $850{ }^{\circ} \mathrm{C}$. In the present case, nevertheless, no intermetallic phases, except the $\mathrm{Ni}(\mathrm{W})$, was found at the interface, for the both 850 and $900{ }^{\circ} \mathrm{C}$ joints. EPMA analysis indicated that the tungsten concentration was below 12 at. \% for these two joints. Similar to the present experimental results, Xu et al. (1991) did not find any intermetallic compounds between $\mathrm{W}$ and $\mathrm{Ni}$, apart from $\mathrm{Ni}(\mathrm{W})$, for the joint bonded below $900{ }^{\circ} \mathrm{C}$. The formation of Ni-rich solid solution $\mathrm{Ni}(\mathrm{W})$ is not difficult to 
understand, for the large solubility of tungsten in nickel (about $40 \mathrm{wt} \%$ at $900{ }^{\circ} \mathrm{C}$ ). The possible reasons for the absence of intermetallic phases at W/Ni interface are: 1) the intermetallic phases have large incubation periods; 2) the flux of tungsten and nickel atoms entering the intermetallic phases less than those leaving these phases; and 3) insufficient longer holding time or relatively low joining temperature was employed. Hence, the expected intermetallic phases could not grow even after nucleation under short holding time and/or low joining temperature. However, an interesting result has also been reported by Batra et al. (2004), where $\mathrm{NiW}_{2}$ phase was found between electroplated $\mathrm{Ni}$ and $\mathrm{W}$ when the $\mathrm{W} / \mathrm{Ni} / \mathrm{Cu}$-alloy joints after bonded at $850{ }^{\circ} \mathrm{C}$ for $1 \mathrm{~h}$. This may be attributed to the different processes used. In the present experiment, Ni foil was used as interlayer; while the Ni layer was obtained by electroplating by Batra et al.. The deposition process may drive the interfacial reaction. Additionally, the longer holding time or higher joining temperature may promote the formation of intermetallics. For example, Zhong et al. (2009) identified the presence of $\mathrm{Ni}_{4} \mathrm{~W}$ phase by XRD for the joint bonded at $900{ }^{\circ} \mathrm{C}$ for $2 \mathrm{~h}$, and the joint bonded at $950{ }^{\circ} \mathrm{C}$ for $1.5 \mathrm{~h}$ (see Fig. 1(c)). For the Ni/FS interface, neither iron nor chromium (the major alloying elements of FS) formed intermediate phases with nickel. This is attributed to the good compatibility between steel and nickel which predicted in $\mathrm{Fe}-\mathrm{Ni}$ and $\mathrm{Cr}-\mathrm{Ni}$ phase 
diagrams (Yu et al. 1987). The solid solution type elemental concentration profiles (Fig.

2 (b)) indicated that the extent of diffusion of chemical species ( $\mathrm{Fe}, \mathrm{Ni}, \mathrm{Cr}$ ) were limited within the respective mutual solid solubility. A similar result has been reported by Kundu and Chatterjee (2006), who found that the interfacial microstructure were similar for $\mathrm{Ni} /$ steel interfaces bonded with different holding times.

\subsection{Joints tensile strength and fracture surface observation}

The tensile specimens which cut from the bonded jonts were tested in an

Instron testing machine in order to evaluate the joint strength, and the results are present in Fig. 4. At low joining temperature, for example, $850^{\circ} \mathrm{C}$, the strength was relatively low because the yield strength of the bonded materials at the interfaces were still high and the extent of diffusion of chemical species were limited at interfaces. As a result, some mating surfaces were lack of contact (in particular at the edge of the joint). The existence of such region demonstrates that the void closure processes in the interface did not complete at this temperature. However, it is worth mentioning that either higher bonding pressure or longer holding times may promote the interfacial contact and elemental diffusion. With increasing the bonding temperature to $900{ }^{\circ} \mathrm{C}$, tensile strength 
was enhanced and reaches the maximum strength (see Fig. 4). The increased contact area between the mating surfaces and the promoted interdiffusion of the chemical species at the interfaces are believed to contribute to the increase of strength.

A further rise in processing temperature to $950{ }^{\circ} \mathrm{C}$, the better contact of the mating surface and enhanced interdiffusion of the chemical species at the interfaces compared to that of bonded at other joining temperatures. However, the tensile strength of the joints showed a slightly decrease in comparison with that of $900{ }^{\circ} \mathrm{C}$ joint. The decrease in the strength may be due to the growth of the diffusion zone and residual stress resulted from CTE mismatch between $\mathrm{W}$ and $\mathrm{Ni}(\mathrm{W})$, and between $\mathrm{Ni}(\mathrm{W})$ and $\mathrm{Ni}$. The contractions of the $\mathrm{W}, \mathrm{Ni}(\mathrm{W})$, and $\mathrm{Ni}$ during cooling from the joining temperature are different since their inherently different CTE, which resulted in residual stress at the W/Ni interface. As a result, the strength decreased. The spread of strength values observed for the joints probably credited to the spread on strength level of the W itself, owing to its brittle nature and sensitivity of impurity distribution. The deformation of the specimen introduced during diffusion bonding increased from 3 to $15 \%$ when the joining temperature increased from 850 to $950{ }^{\circ} \mathrm{C}$. Despite the tensile strengths of the joints are lower than that of annealed W (550-620 MPa) and of FS ( 400 MPa) used in this work, a W/FS joint with appropriate mechanical strength and acceptable 
deformation $(\sim 5 \%)$ could be obtained for specimens bonded at $900{ }^{\circ} \mathrm{C}$ under $10 \mathrm{MPa}$ for $1.5 \mathrm{~h}$.

It is known that the pre-induced residual stresses, which located adjacent to the joining interface in low CTE material, as demonstrated by Conzone et al. (1997), play an important role in determining the mechanical behavior of dissimilar material joints. It was found that the specimens fractured at $\mathrm{W}$ near the $\mathrm{W} / \mathrm{Ni}$ interfaces during tensile testing, as expected on the base of CTE mismatch in the W/FS joints. Some cracks also were observed at the Ni/FS interface after tensile test but no failure occurred, indicating that the strength of Ni/FS interface was higher that of W/Ni interface. Some typical fractured surfaces on the Ni side were given in Fig. 5, which exhibited polycrystalline microstructures with some fragments. The fractured surface is characterized by the appearance of the faceted grains, suggesting that the joints failed in an intergranular (in W) and transgranular (in Ni(W) and Ni) mode. For 850 and $900{ }^{\circ} \mathrm{C}$ joint, the fractured surface mostly remained at one level, which indicates that the interface failed by the fast propagation of microcracks at the $\mathrm{W}$ grain boundaries. For the $950{ }^{\circ} \mathrm{C}$ joint, the fracture took place predominantly in $\mathrm{W}$, and some in both $\mathrm{Ni}_{4} \mathrm{~W} / \mathrm{Ni}(\mathrm{W})$ and $\mathrm{Ni}$, as shown in Fig. 5(c), showing that the crack propagated into the reaction products. This may be attributed to the existence of the brittle $\mathrm{Ni}_{4} \mathrm{~W}$, which was not detected in 850 or $900{ }^{\circ} \mathrm{C}$ 
joint. Although the morphology of fracture surface is slightly different from that of 850 or $900{ }^{\circ} \mathrm{C}$ joint, the failure in $950{ }^{\circ} \mathrm{C}$ joint during tensile testing may show a similar behavior, i.e., the crack initiated in $\mathrm{W}$ near the $\mathrm{W} / \mathrm{Ni}$ interface due to the residual stress concentration, and then propagated rapidly along the $\mathrm{W}$ grain boundaries and into both $\mathrm{Ni}_{4} \mathrm{~W} / \mathrm{Ni}(\mathrm{W})$ and $\mathrm{Ni}$.

\subsection{Hardness distribution across the interfaces}

The micro-mechanical properties of ceramic/metal, metal/metal bonded interfaces can be evaluated by nano-indentation test, which is a useful technique to evaluate the mechanical properties of either films or small volumes of material. The micromechanical characterization at the $\mathrm{W} / \mathrm{Ni}$ and $\mathrm{Ni} / \mathrm{FS}$ interfaces were assessed via hardness tests, which were done on the polished cross-section of the joint bonded at 950 ${ }^{\circ} \mathrm{C}$ for $1.5 \mathrm{~h}$ using a diamond Berkovich indenters tip with $3 \mathrm{gf}$ load for each indent in the present study.

Figure 6 illustrates the selected load-displacement curves for the indents of the $\mathrm{W}, \mathrm{Ni}(\mathrm{W}), \mathrm{Ni}$, diffusion zone (DZ) between $\mathrm{Ni}$ and FS, and FS. The hardness of $\mathrm{Ni}_{4} \mathrm{~W}$ could not be evaluated due to its volume fraction is too small in the reaction zone. 
During the hardness tests, the indenter penetrated the surface of the material as the loading was increased to a maximum load of $3 \mathrm{gf}$, at which point the indenter was then unloaded. The displacement into the surface of DZ $(440 \mathrm{~nm})$ is less than that of into the $\mathrm{Ni}(690 \mathrm{~nm})$ or FS $(603 \mathrm{~nm})$ under the same load, which implies that the hardness of the DZ is higher than that of Ni or FS. Similarly, the displacement into W (394 nm) is smaller than that of into $\mathrm{Ni}(\mathrm{W})(411 \mathrm{~nm})$ or $\mathrm{Ni}$, which is consistent with the corresponding hardness results presented in Fig. 7.

Figure 7(a) and (b) shows the variation of hardness across the W/Ni (from $\mathrm{W}$ to $\mathrm{Ni}$ interlayer) and Ni/FS interfaces (from Ni interlayer to FS), respectively. The measured hardness for $\mathrm{W}$ is about 7.2 GPa which is comparable with that reported by Suzuki et al. (2006). The hardness value of the Ni interlayer is similar to that previously observed by Miranzo et al.(2004). Although the hardness of ferritic steel has not been reported in open literatures, it is within the hardness range of $316 \mathrm{~L}$ stainless steel and F82H steel, which was reported by Zhang et al. (2007) and Suzuki et al. (2006), respectively. It can be noted in Fig. 7(a) that the hardness of $\mathrm{Ni}(\mathrm{W})$ is higher than that of Ni. Such hardness increase is attributed to the nature of solid solution phase. In addition, the hardness of DZ is higher than that of Ni or FS (see Fig. 7(b)), which is also believed to result from the effect of solid solution strengthening. 


\section{Conclusions}

The effect of joining temperature on interfacial microstructure and mechanical properties of diffusion bonded W/FS joints with a Ni interlayer has been investigated. From the results obtained, the following conclusions can be drawn:

1. Diffusion bonding of $\mathrm{W}$ to ferritic steel was successfully carried out using a $\mathrm{Ni}$ interlayer.

2. Microstructure analysis indicated that a good bonding at both $\mathrm{W} / \mathrm{Ni}$ and $\mathrm{Ni} / \mathrm{FS}$ interfaces was formed. For 850 and $900{ }^{\circ} \mathrm{C}$ joints, only the $\mathrm{Ni}(\mathrm{W})$ solid solution was found at the $\mathrm{W} / \mathrm{Ni}$ interface; besides the $\mathrm{Ni}(\mathrm{W})$, a small amount of $\mathrm{Ni}_{4} \mathrm{~W}$ also grew between $\mathrm{W}$ and $\mathrm{Ni}(\mathrm{W})$ for $950{ }^{\circ} \mathrm{C}$ joint. The smoothly elemental concentration variation at the Ni/FS interface indicated the absence of intermetallic compounds for the joining temperatures of interest.

3. The strength of the joint increased with increasing the joining temperature up to $900{ }^{\circ} \mathrm{C}(\sim 200 \mathrm{MPa})$ and then decreased.

4. All specimens fractured in $\mathrm{W}$ near the $\mathrm{W} / \mathrm{Ni}$ interface which is the residual stress concentration region in the joints, during tensile test, in a brittle fracture mode. 
5. Hardness in both the W/Ni and Ni/FS diffusion zones was greatly increased due to

the formation of solid solution phases.

\section{Acknowledgements}

This work was partly supported by Ministry of Education, Culture, Sports, Science and Technology (MEXT), Japan. The authors are grateful to Associate Professor H.

Kishimoto for technical assistance and helpful discussion.

\section{References}

Norajitra, P., Giniyatulin, R., Holstein, N., Ihli, T., Krauss, W., Kruessmann, R., 2005. Status of He-cooled divertor development for DEMO. Fusion Eng. Des. 75-79, 307-311.

Gervash, A., Giniyatulin, R., Ihli, T., Krauss, T., Makhankov, T., Mazul, I., 2007. Fabrication of a He-cooled divertor module for DEMO reactor. J. Nucl. Mater. 367-370, 1472-1475.

Norajitra. P., Boccaccini, L.V., Gervash, A., Giniyatulin, R., Holstein, N., Ihli, T. 2007. Development of a helium-cooled divertor: Material choice and technological studies. J. Nucl. Mater. 367-370, 1416-1421.

Kalin, B.A., Fedotov, V.T., Sevrjukov, O.N., Kalashnikov, A.N., Suchkov, A.N., Moeslang, A., 2004. Development of rapidly quenched brazing foils to join tungsten alloys with ferritic steel. J. Nucl. Mater. 329-333, 1544-1548.

Kalin, B.A., Fedotov, V.T., Sevrjukov, O.N., Kalashnikov, A.N., Suchkov, A.N., Moeslang, A., 2007. Development of brazing foils to join monocrystalline tungsten alloys with ODS-EUROFER steel. J. Nucl. Mater. 367-370, 1218-1222.

Greuner, H., Bolt, H., Böswirth, B., Lindig, S., Kühnlein, W., Huber, T., 2005. Vacuum plasma-sprayed tungsten on EUROFER and 316L: Results of characterization and thermal loading tests. Fusion Eng. Des. 75-79, 333-338.

Hirose, T., Shiba, K., Ando, M., Enoeda, M., Akiba, M., 2006. Joining technologies of reduced activation ferritic/martensitic steel for blanket fabrication. Fusion Eng. Des. 81, 645-651. 
Kundu, S., Chatterjee S., 2006. Interfacial microstructure and mechanical properties of diffusionbonded titanium-stainless steel joints using a nickel interlayer. Mater. Sci. Eng. A, 425, 107-113.Yu, J.Q., Yi, W.Z., Chen, B.D., Chen, H.J., 1987. Second Phase Diagrams, first ed. Science and Technology, Shanghai, pp.498.

Xu, Y, Laabs, F.C, Beaudry, B.J, Gschneidner K.A. Jr., 1991. Pressure-assisted reaction bonding between $\mathrm{W}$ and $\mathrm{Si}_{80} \mathrm{Ge}_{20}$ alloy with $\mathrm{Ni}$ as the interlayer. J. Appl. Phys. 69, 4292-4299.

Batra, I.S., Kale, G.B., Saha, T.K., Ray, A.K., Derose, J., Krishnan, J., 2004. Diffusion bonding of a $\mathrm{Cu}-\mathrm{Cr}-\mathrm{Zr}$ alloy to stainless steel and tungsten using nickel as an interlayer. Mater. Sci. Eng. A 369, 119-123.

Zhong, Z.H., Hinoki, T. Kohyama, A. 2009. Effect of holding time on the microstructure and strength of tungsten/ferritic steel joints diffusion bonded with a nickel interlayer. Mater. Sci. Eng. A, 518, 167-173.

Yu, J.Q., Yi, W.Z., Chen, B.D., Chen, H.J., 1987. Second Phase Diagrams, first ed. Science and Technology, Shanghai, pp.368\&322.

Conzone, S.D., Butt, D.P., Bartletta, H., 1997. Joining $\mathrm{MoSi}_{2}$ to $316 \mathrm{~L}$ stainless steel. J. Mater. Sci. 32, 3369-3374.

Miranzo, P., Osendi, M.I., Vergara, I., 2004. Mechanical properties of the Ni filler metal layer in $\mathrm{Si}_{3} \mathrm{~N}_{4}$ joints measured by nanoindentation. Surf. Interface Anal. 36, 649-653.

Zhang, P.C., Bai, B., Shen, L., Zhou, J., 2001. Distribution of the composition and micromechanical properties of Be/316L stainless steel following diffusion bonding. Surf. Interface Anal. 32, $88-90$.

Suzuki, S., Ezato, K., Hirose, T., Sato, K., Yoshida, H., Enoeda, M., 2006. First wall and divertor engineering research for power plant in JAERI. Fusion Eng. Des. 81, 93-103. 


Table 1 - Chemical composition (wt.\%) of the used base metals
\begin{tabular}{|ccccccccccc} 
Material & Fe & W & C & Si & Mn & Ni & Mo & Cr & N & O \\
\hline FS & bal. & - & 0.07 & 0.63 & 0.25 & 0.10 & - & 16.22 & - & - \\
\hline W & - & bal. & 0.02 & - & - & - & - & - & 0.01 & 0.01 \\
\hline
\end{tabular}

\section{Table 2 - Tensile properties of the used base metals at room temperature}

$\begin{array}{llll}\text { Material } & \text { Yield stress (MPa) } & \text { Ultimate tensile strength (MPa) } & \text { Fracture elongation (\%) }\end{array}$

\begin{tabular}{cccc}
\hline FS & 250 & 530 & 20 \\
\hline $\mathrm{W}$ & - & $800-1000$ & $<0.4$ \\
\hline
\end{tabular}




\section{Figure captions}

Fig. 1. SEM micrographs of the W/Ni interface of the specimens bonded at (a) $850^{\circ} \mathrm{C}$,

(b) $900{ }^{\circ} \mathrm{C}$, and (c) $950^{\circ} \mathrm{C}$.

Fig. 2. Elemental concentration profiles of (a) $\mathrm{W}$ and $\mathrm{Ni}$ across the $\mathrm{W} / \mathrm{Ni}$ interface, and

(b) $\mathrm{Fe}, \mathrm{Ni}$, and $\mathrm{Cr}$ across the Ni/FS interface. The joint was bonded at $950{ }^{\circ} \mathrm{C}$.

Fig. 3. SEM micrographs of the Ni/FS interface of the specimens bonded at (a) $850{ }^{\circ} \mathrm{C}$,

(b) $900{ }^{\circ} \mathrm{C}$, and (c) $950{ }^{\circ} \mathrm{C}$.

Fig. 4. Tensile strength of the W/FS joint as a function of joining temperature.

Fig. 5. Representative fractured surfaces on the FS side, for the samples bonded at (a)

$850{ }^{\circ} \mathrm{C},(\mathrm{BEI}),(\mathrm{b}) 900{ }^{\circ} \mathrm{C}(\mathrm{BEI})$, and (c) $950{ }^{\circ} \mathrm{C}$ (SEI), showing predominantly

intergranular fracture in W.

Fig. 6. Nano-indentation load-displacement curves for some selected positions.

Fig. 7. Hardness distribution along the cross-section of (a) W/Ni and (b) Ni/FS interface, for the joint diffusion bonded at $950{ }^{\circ} \mathrm{C}$ for $1.5 \mathrm{~h}$. 
Fig. 1

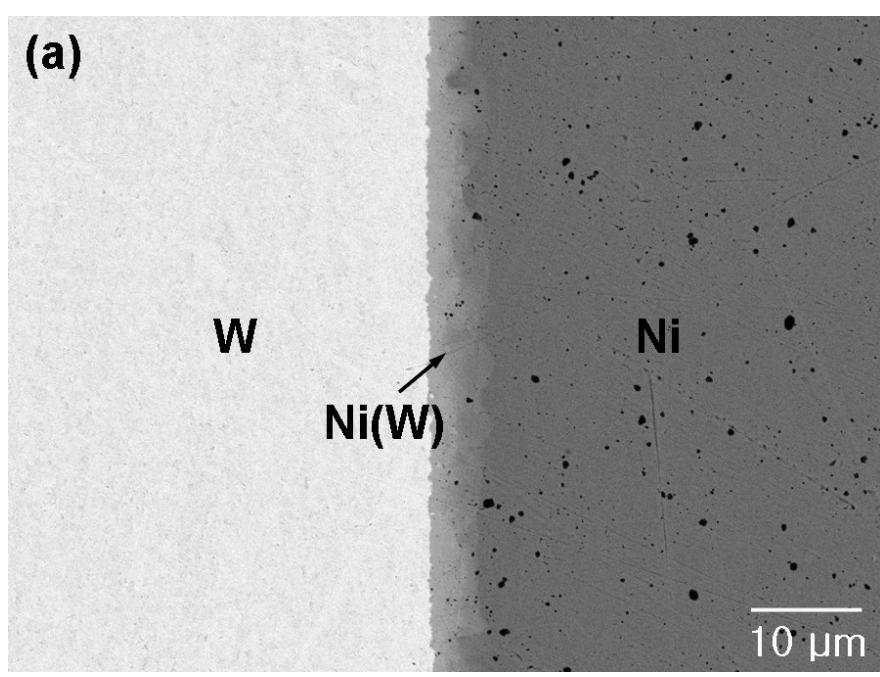

(b)

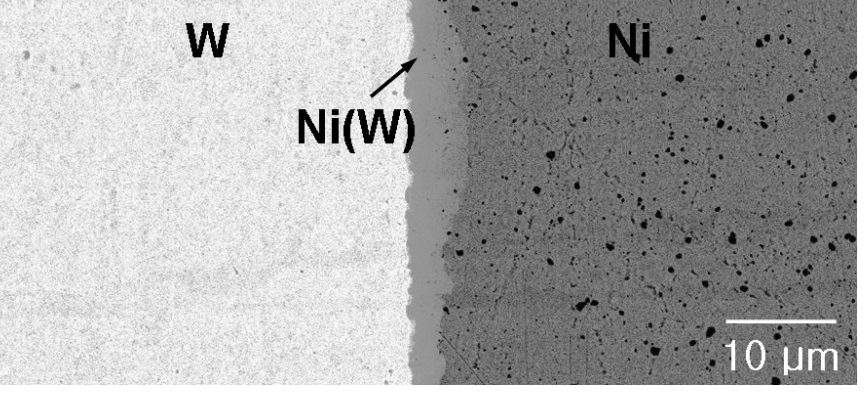

(c)

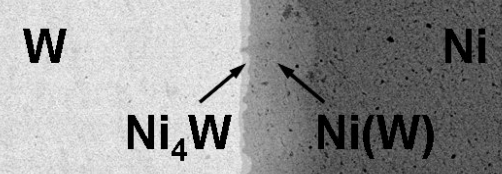


Fig. 2.
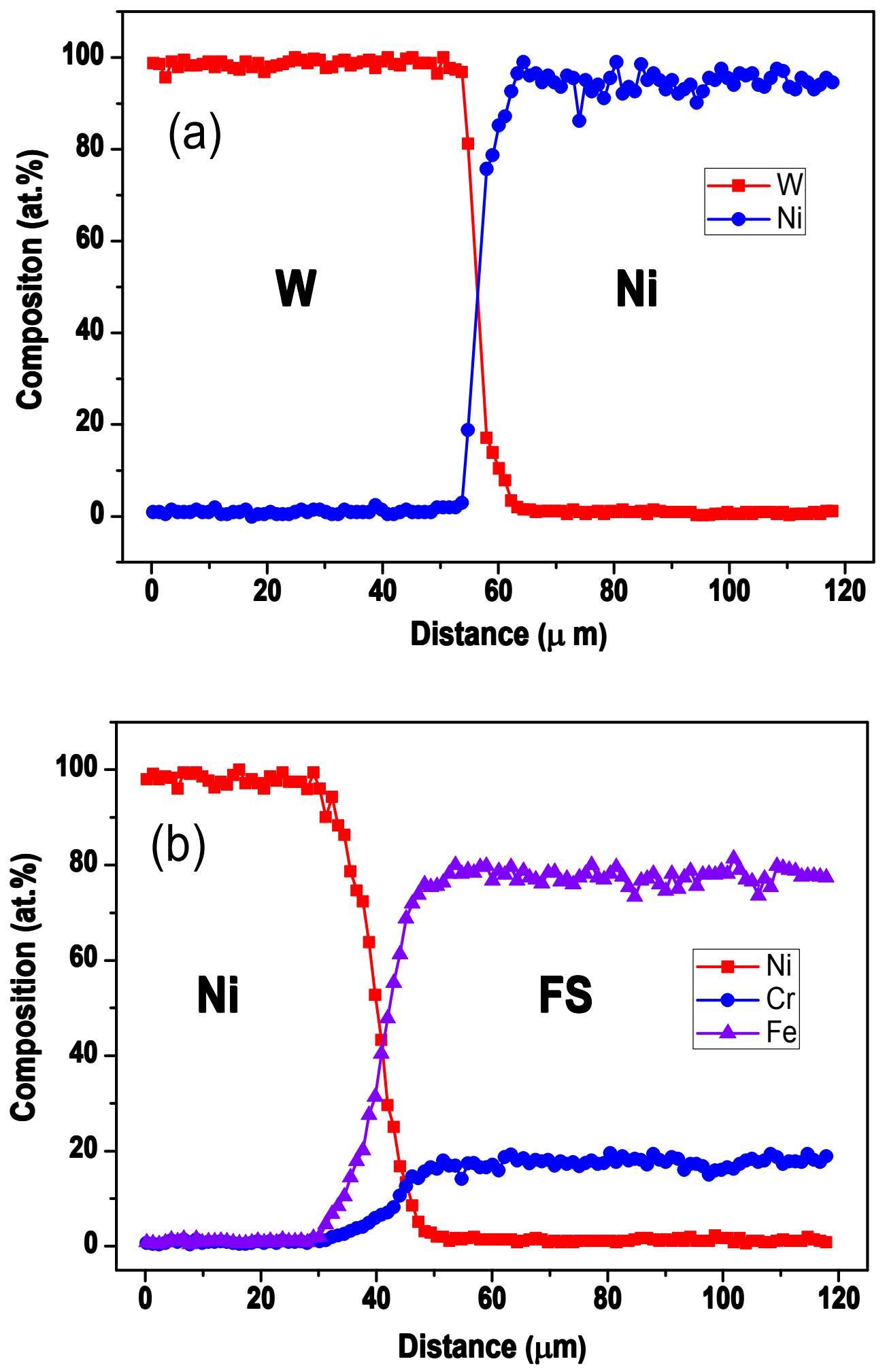
Fig. 3
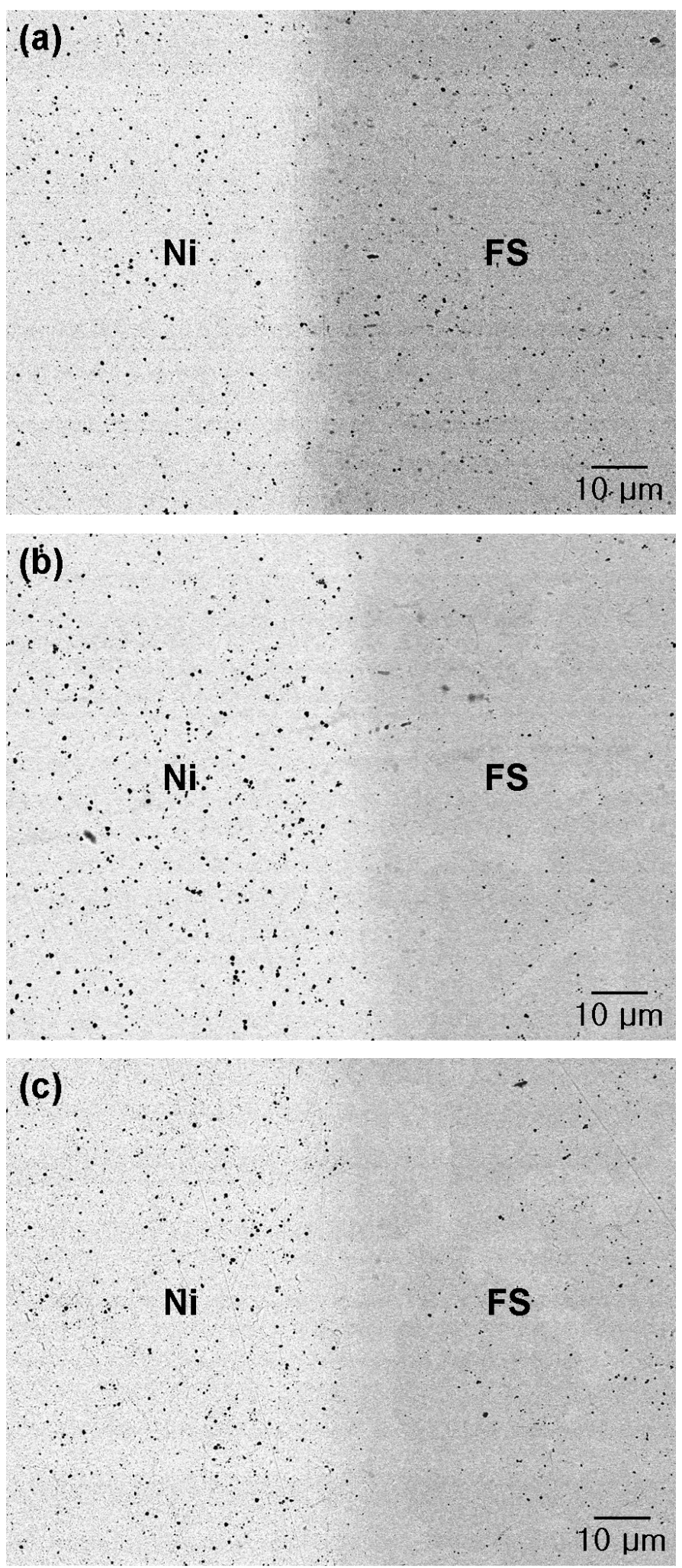
Fig. 4

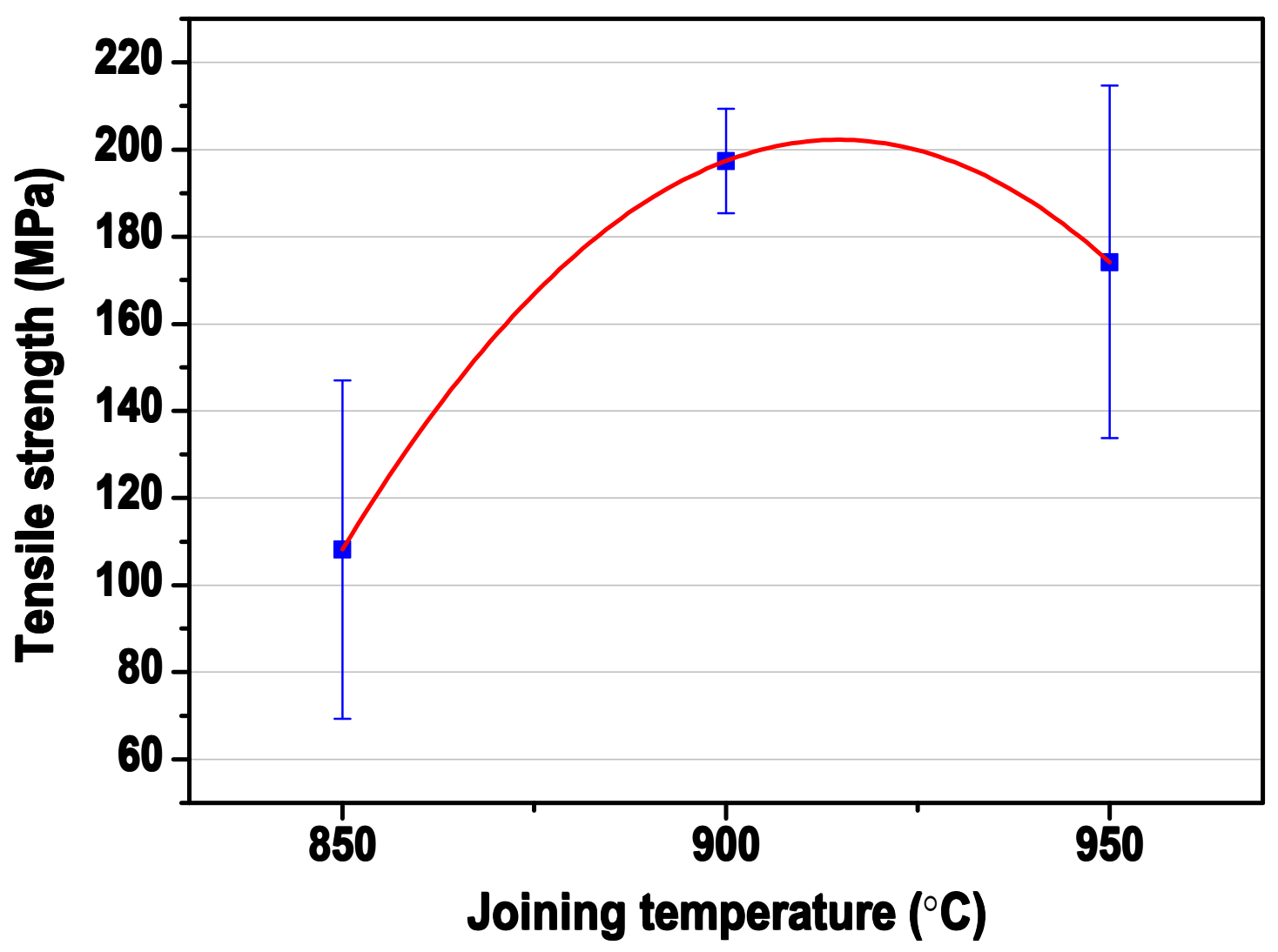


Fig. 5
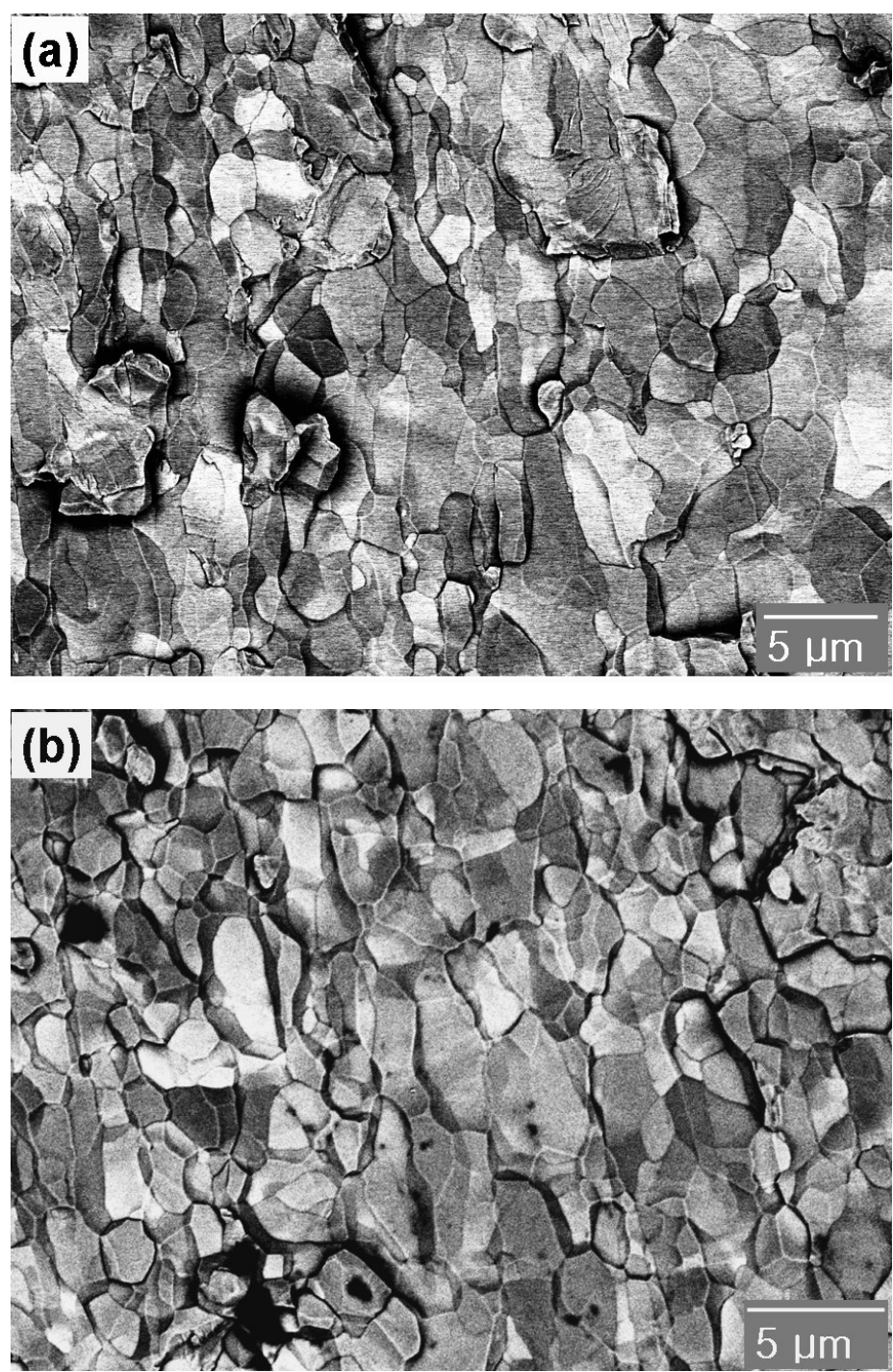

(c)

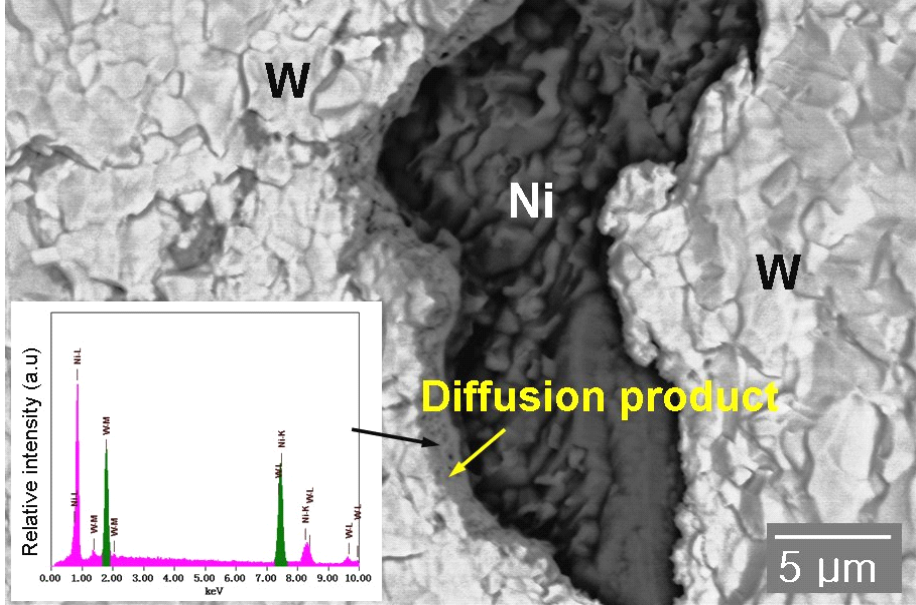


Fig. 6

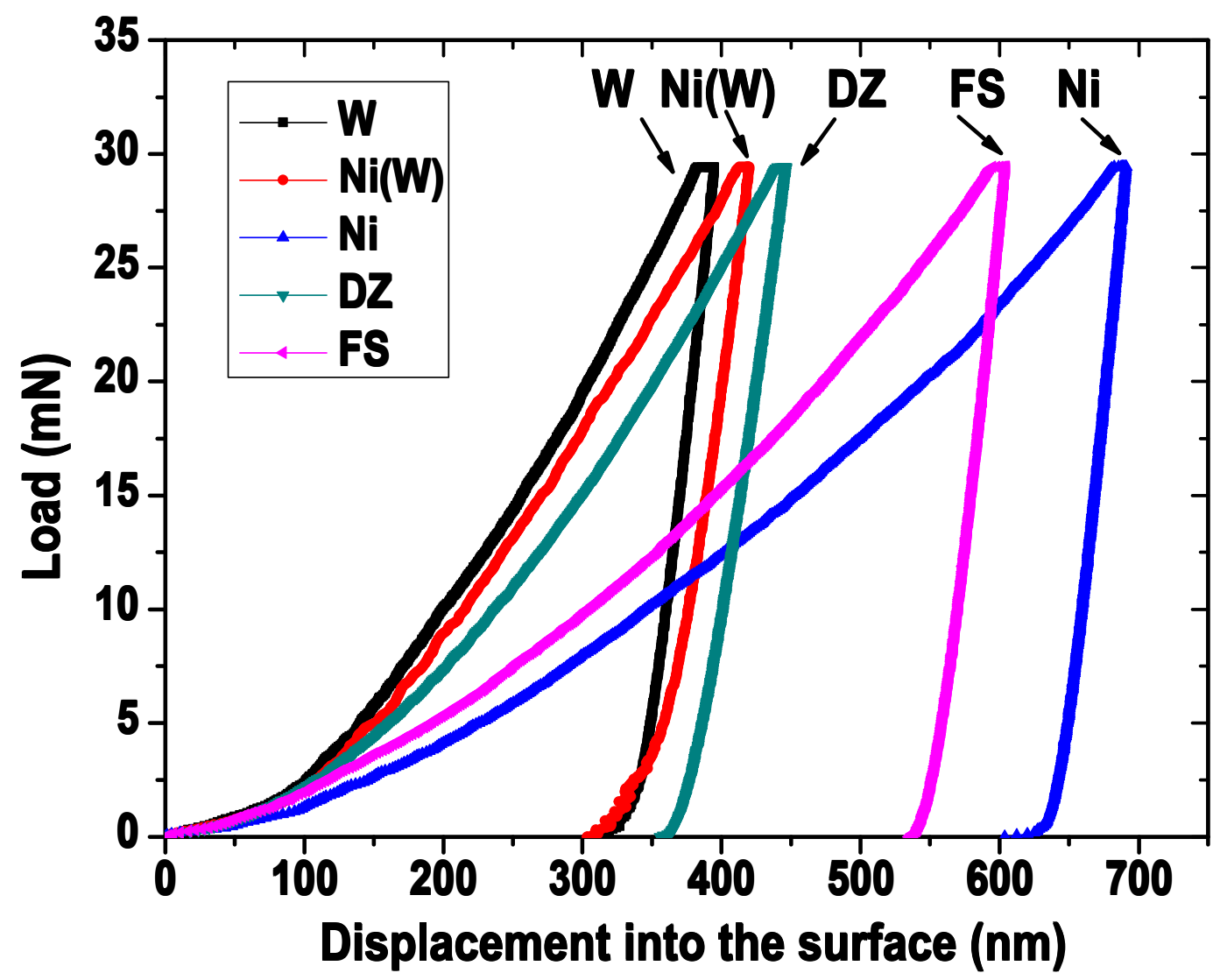


Fig. 7
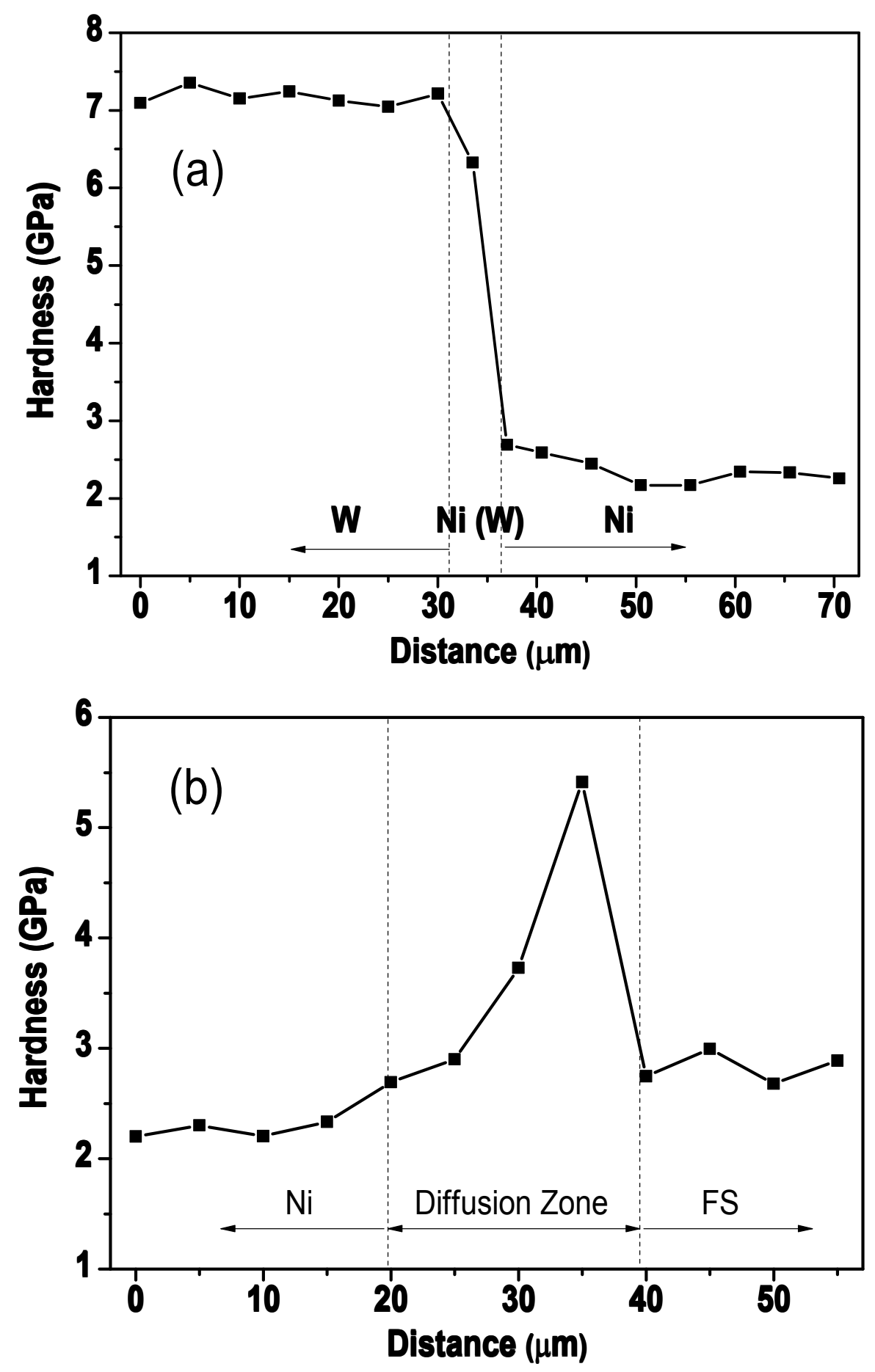